1. MBBS, M.Phil Microbiology Senior Demonstrator Pathology

Rahbar Medical \& Dental College, Lahore.

2. MBBS, M.Phil Microbiology Professor Pathology

Amna Inayat Medical College, Lahore.

3. MBBS, M.Phil Microbiology Professor Pathology Azra Naheed Medical College, Lahore.

4. MBBS, M.Phil Microbiology Professor Pathology

Combined Military Hospital Lahore. National University of Medical Sciences, Pakistan.

5. MBBS, M.Phil Microbiology Assistant Professor Pathology Gujranwala Medical College, Gujranwala.

6. MBBS, MCPS, DTCD, MPH, MRIEH, MHSM, MS, Ph. D (Epidemiology) MPA.

Senior Demonstrator Community Medicine

Rahbar Medical \& Dental College, Lahore.

Correspondence Address:

Dr. Aneela Khawaja

Department of Pathology

129-B, Street 35, Phase 1, DHA,

Lahore.

draneelakh@gmail.com

0344-4251171

Article received on:

22/05/2019

Accepted for publication:

$10 / 10 / 2019$

\section{DETECTION OF MECA GENE BY LATEX AGGLUTINATION AND ITS MOLECULAR ANALYSIS BY PCR IN METHICILLIN RESISTANT STAPHYLOCOCCUS AUREUS.}

\begin{abstract}
Aneela Khawaja ${ }^{1}$, Iffat Javed ${ }^{2}$, Sohaila Mushtaq ${ }^{3}$, Saeed Anwar ${ }^{4}$, Faiqa Arshad ${ }^{5}$, Naseer Ahmad Raja ${ }^{6}$
ABSTRACT... Objectives: To compare detection of mecA gene in methicillin resistant isolates of Staphylococcus aureus by latex agglutination and PCR; by assessing the sensitivity and specificity of both methods. Study Design: Descriptive Cross-Sectional study. Setting: Pathology Department, Post Graduate Medical Institute, Lahore. Period: From January 2015 to December 2015; according to standard operating procedures at Microbiology laboratory. Material \& Methods: A total 713 consecutive, non-duplicate isolates of Staphylococcus aureus were processed. Methicillin resistance was determined using cefoxitin $(30 \mu \mathrm{g})$ by Kirby-Bauer method using CLSI guideline (2016), latex agglutination method; and PCR for mecA gene. Results: The results showed that out of 713 Staphylococcus aureus isolates, $92(12.90 \%)$ isolates were resistant to cefoxitin and were labelled as MRSA. majority MRSA isolates recovered from pus $(44.57 \%)$ and wound swab $(20.65 \%)$, followed by blood (13.04\%), fluid $(8.70 \%)$, CSF $(4.35 \%)$, CVP (3.26\%), HVS (3.26\%) and tracheal secretion (2.17\%). By latex agglutination method, 87 $(94.50 \%)$ were positive for PBP2a; while on PCR mecA gene was detected only in $82(89.10 \%)$ MRSA isolates. When assessed with PCR (gold standard) the sensitivity and diagnostic accuracy of latex agglutination was $100 \%$ and $94.57 \%$, respectively. Conclusion: Latex agglutination test can be employed as rapid and reliable diagnostic technique in MRSA isolates for mecA gene detection, where resources for molecular methods are inadequate. This can effectually lessen the misdiagnosis of resistant strains, and over/ ill-use of antibiotics.
\end{abstract}

Key words: Cefoxitin, Latex Agglutination, mecA Gene, Methicillin Resistant Staphylococcus Aureus (MRSA), Polymerase Chain Reaction (PCR).

Article Citation: Khawaja A, Javed I, Mushtaq S, Anwar S, Arshad F, Raja NA. Detection of MECA gene by latex agglutination and its molecular analysis by PCR in methicillin resistant Staphylococcus aureus. Professional Med J 2020; 27(7):1363-1370. DOI: 10.29309/TPMJ/2020.27.07.3752

\section{INTRODUCTION}

The acquisition of antibiotic resistance has led to progression of Staphylococcus aureus infections in this antibiotic era. Evolution of lethal superbugs and loss of "miracle drug" effectiveness worsens the battle against serious bacterial infections, further complicating the treatment options. The loss of efficacy against common pathogens has led to an option towards more expensive antibiotic drugs in high-income countries, as well as increased morbidity and mortality in lowincome and middle-income countries. Antibiotic drug consumption is a major driver of antibiotic resistance. ${ }^{1,2}$

Antimicrobial resistance develops as a natural phenomenon when the infecting germ is not killed or inhibited by the drug being used by the patient at required therapeutic levels. Infections with resistant pathogens are challenging to treat, demanding costly and at times toxic substitutes. ${ }^{3}$

The World Health Organization (WHO) defines antimicrobial resistance to human pathogens as a universal health challenge. Antimicrobial resistance makes diseases harder and more expensive to treat not only in developed countries but progressing towards financial crisis in undeveloped countries. Drug resistant infections are treating the economic future of the biosphere. Human action is making AMR worse. The reasons are: Poor infection control in hospitals; inappropriate food handling; Poor sanitary conditions; and most important misuse 
and/or overuse of antimicrobial drugs in humans and in breeding crops and animals. ${ }^{4,5}$

Among multidrug resistant infections, methicillin resistant Staphylococcus aureus (MRSA) is the foremost challenging pathogen, accounting for $40-70 \%$ of the Staphylococcus aureus infections worldwide. ${ }^{6}$

Methicillin-resistant Staphylococcus aureus (MRSA) infections are recognized globally both in developed and developing countries as a cause of frequent hospitalizations and invasive infections associated with remarkable high morbidity, high mortality and increased treatment costs. In recent years, developing multidrug-resistant strains of Staphylococcus aureus (MDRSA) have made treatment of Staphylococcus aureus infections more prolonged, troublesome and distressing. ${ }^{7}$

It is stated that methicillin resistance in Staphylococcus aureus has been associated with modifications in the penicillin binding proteins (PBPs) subsequently generating an additional penicillin-binding protein, PBP2a or PBP2'. This PBP2a is encoded by the mecA gene which is carried on a large genomic island labeled SCCmec. Methicillin resistance in Staphylococcus aureus is due to the acquisition of mecA gene to a mobile genetic element called Staphylococcal cassette chromosome mec (SCCmec). Integration and acquisition of a staphylococcal cassette chromosome mec (SCCmec) element into the chromosome converts drug-sensitive staphylococcal lineages into the notorious methicilinresistant staphylococcus aureus (MRSA). ${ }^{8}$

Prevention and control of MRSA transmission and infection are vital in decreasing the resistant infections, mortality and medical cost. Beside the standard precautions, the effective approaches helpful in reducing MRSA infection rate are active surveillance, decolonization, screening and isolation. Strict implementation of standard infection control practices is helpful in diminishing the carriage and transmission of MRSA in both hospital and community setting. ${ }^{9}$
At present, methicillin resistant strains of Staphylococcus aureus are resistant to all presently existing $\beta$-lactam agents, including semisynthetic penicillin's, i.e., methicillin, oxacillin and nafcillin, the combination of penicillin and $\beta$-lactamase inhibitors and as well as all of the cephalosporins, carbapenems, aminoglycosides, macrolides, chloramphenicol, tetracyclines and fluoroquinolones. ${ }^{10}$

Currently, the commonly used phenotypic methods for detection of MRSA are conventional disc diffusion method (Modified Kirby-Bauer and Stokes methods); broth microdilution method determining minimal inhibitory concentration (MIC); E Test method; breakpoint method; agar dilution method (oxacillin/methicillin screen agar, mannitol salt agar, isosensitest agar, chromogenic agar). ${ }^{11}$ Latex agglutination method detects mecA gene product i.e., PBP2a. ${ }^{12}$ The genotypic methods confirm the presence or absence of mecA gene in methicillin resistant Staphylococcus aureus isolates by polymerase chain reaction. ${ }^{13}$

MRSA is considered to be a potential "Super Bug" which is a major threat to hospital infection control. Laboratory diagnosis and susceptibility testing are essential steps in accurate detection, treatment, control and prevention of MRSA infections. Tests with cefoxitin do not appear to be affected to the extent as oxacillin by hyperproduction of penicillinase. In disc diffusion tests, hyper-producers of penicillinase may show small methicillin or oxacillin zones of inhibition, whereas most true methicillin/oxacillin-resistant isolates give no zone. ${ }^{14}$

External parameters that influence the degree of heterogeneity and resistance include inoculum size, salt concentration, $\mathrm{pH}$, composition of medium, osmolarity and temperature. ${ }^{15}$

Latex agglutination test is considered better than the conventional phenotypic methods as it is not generally biased by the environmental conditions. In this test latex particles sensitized with specific monoclonal antibodies directed against PBP2a present in MRSA cause agglutination. The latex 
agglutination is a rapid test and provides good preliminary screening with high sensitivity and specificity. ${ }^{16}$

PCR is a gold standard confirmatory test with high sensitivity and specificity but is expensive and is not available in most of the routine laboratories. Regarding accurate detection of MRSA, the latex agglutination is a simple and rapid test for identification of mecA gene. It can serve as a good preliminary screen with high sensitivity and specificity equivalent to PCR. It can be easily performed in most of the laboratories in our setup.

This study has been organized to evaluate the methicillin resistance among clinical isolates of Staphylococcus aureus by latex agglutination and PCR as a gold standard; by assessing the sensitivity and specificity of both methods.

\section{MATERIAL \& METHODS}

This descriptive cross-sectional study was conducted in Pathology Department of PGMI, Lahore; during the period from January 2015 to December 2015.

This study has been structured to compare detection of mecA gene in methicillin resistant clinical isolates of Staphylococcus aureus by latex agglutination and PCR; by assessing the sensitivity and specificity of both methods.

Clinical isolates of Staphylococcus aureus resistant to cefoxitin were only included in the study project. Clinical isolates of Staphylococcus aureus; sensitive to cefoxitin were not included in the study project.

Clinical specimens were received from patients admitted in different clinical wards of Lahore General Hospital (LGH). The specimens were processed according to standard operating procedures in microbiology test center of Pathology department, PGMI, Lahore.

All the specimens were inoculated on blood agar and McConkey agar (prepared as instructions given by the manufacturer). The plates were incubated at $35-37^{\circ} \mathrm{C}$ aerobically. Following standard microbiological techniques; preliminary identification of Staphylococcus aureus isolates was done by observing the colony morphology on blood agar plates, finding gram positive cocci in clusters on Gram stain and positive Catalase test. Additional biochemical tests i.e., coagulase and DNA-ase were ran for the affirmation of Staphylococcus aureus. ${ }^{17}$

Screening was implemented on all isolates of Staphylococcus aureus. The phenotypic resistance to methicillin was ascertained by modified Kirby-Bauer using $30 \mu \mathrm{g}$ cefoxitin disc (Oxoid) on Muller Hinton agar according to the Clinical and Laboratory Standards Institute (CLSI, 2016) guiding principles. For each strain, a bacterial suspension adjusted according to 0.5 McFarland turbidity standards was prepared and inoculated on Mueller Hinton agar. The plates were incubated at $35^{\circ} \mathrm{C}$ and zone of inhibition was determined after 24-hour time. The outcomes were read agreeing to CLSI criteria, i.e. zone of $\leq$ $21 \mathrm{~mm}$ was considered as resistant and $\geq 22 \mathrm{~mm}$ was considered to be sensitive. Two standard strains, MRSA ATCC 33591 and MSSA ATCC 25923 were employed as inclusion and exclusion check respectively. ${ }^{18}$

Isolates of Staphylococcus aureus showing resistance to cefoxitin (MRSA) were examined for mecA gene outcome (PBP2a) employing latex agglutination kit (Oxoid, DR0900). Procedure followed according to manufacturer's instruction using colonies on Mueller Hinton agar. Latex particles activated with monoclonal antibodies opposed to PBP2a particularly bind with methicillin resistant staphylococci to produce clumping noticeable to the un-aided eye. Methicillin susceptible Staphylococcus aureus (MSSA) does not clump the latex particles. All the components were kept at $2-8^{\circ} \mathrm{C}$. Each strain was tested simultaneously with a negative control latex suspension. ${ }^{19}$

All the MRSA isolates were grown in nutrient broth by incubating in a shaking incubator at $37^{\circ} \mathrm{C}$ for $24 \mathrm{hrs}$. Boiling method was used for DNA extraction. The supernatant was collected and stored at $-20^{\circ} \mathrm{C}$ for $\mathrm{PCR}$ reaction. 
PCR was carried out to confirm the existence of mecA gene in methicillin resistant isolates of Staphylococcus aureus using following primers:

\begin{tabular}{|c|c|c|c|}
\hline Primers & $\begin{array}{c}\text { Oligonucleotide } \\
\text { sequence }\left(\mathbf{5}^{\prime} \mathbf{-} \mathbf{3}^{\prime}\right)\end{array}$ & Specificity & $\begin{array}{c}\text { Product size } \\
\text { (bp) }\end{array}$ \\
\hline & $\begin{array}{c}\text { GTA GAA ATG ACT GAA } \\
\text { CGT CCG ATA A }\end{array}$ & mec A & 310 \\
MecA1 (F) & $\begin{array}{c}\text { CCA ATT CCA CAT TGT } \\
\text { TTC GGT CTA A }\end{array}$ & $\begin{array}{c}\text { TTC GG } \\
\text { MecA }\end{array}$ & \\
\hline
\end{tabular}

Table-I. Primers for mecA gene by PCR Amplification.

DNA Amplification was performed as follows: An initial denaturation step of $5 \mathrm{~min}$ at $94^{\circ} \mathrm{C}$; followed by 35 cycles of denaturation step at $95^{\circ} \mathrm{C}$ for 45 $\mathrm{s}$, annealing step at $58^{\circ} \mathrm{C}$ for $45 \mathrm{~s}$, and extension step at $72^{\circ} \mathrm{C}$ for $45 \mathrm{~s}$; and a final extension at $72^{\circ} \mathrm{C}$ for $5 \mathrm{~min}$. The PCR amplification products (310 bp) were analyzed by electrophoresis on $1.2 \%$ agarose gel stained with ethidium bromide $(10 \mathrm{mg} / \mathrm{ml})$, and visualized under UV light. ${ }^{20}$

For all tests run, Methicillin resistant Staphylococcus aureus (MRSA) ATCC 33591 and Methicillin Sensitive Staphylococcus aureus (MSSA) ATCC 25923 were used as positive and negative controls, respectively.

All the data was entered and analyzed by using SPSS Version 20.0. Sensitivity, specificity, positive predictive value (PPV), negative predictive value (NPV) and diagnostic accuracy (DA) of latex agglutination method was calculated using mecA gene PCR as a gold standard.

\section{RESULTS}

The outcomes of the study revealed distribution of MRSA species recovered from different clinical specimens $(n=92)$. Table-Il of our study reveals distribution of MRSA isolates among different clinical specimens. Statistically the difference was significant $(p<0.05)$ among percentage of MRSA isolates from different clinical specimens.

Among 713 isolates of Staphylococcus aureus, 92 strains exhibited cefoxitin resistance. By latex agglutination technique 87 (94.50\%) MRSA isolates were positive for mecA gene product (PBP2a). So, 5 (5.43\%) mecA -ve isolates were mistakenly recognized as MRSA by cefoxitin disk diffusion method. PCR amplification of all the MRSA isolates was carried out. mecA gene was detected in 82 (89.10\%) MRSA isolates. So, $10(10.90 \%)$ mecA -ve isolates were falsely recognized as MRSA by cefoxitin disk diffusion method (Table-III).

\begin{tabular}{|c|c|c|c|}
\hline \multirow{2}{*}{ Specimen } & \multirow{2}{*}{$\begin{array}{l}\text { No. of } \\
\text { Staphylococcus } \\
\text { Aureus Isolates }\end{array}$} & \multicolumn{2}{|c|}{ MRSA } \\
\hline & & No. & \%age \\
\hline Pus & 328 & 41 & 12.50 \\
\hline Wound Swab & 42 & 19 & 45.24 \\
\hline Blood & 114 & 12 & 10.53 \\
\hline Fluid & 15 & 8 & 53.33 \\
\hline CSF & 22 & 4 & 18.18 \\
\hline CVP Tip & 18 & 3 & 16.67 \\
\hline HVS & 141 & 3 & 2.13 \\
\hline Tracheal Secretion & 33 & 2 & 6.06 \\
\hline Total & 713 & 92 & 12.90 \\
\hline \multicolumn{4}{|c|}{$\begin{array}{l}\text { Table-II. Distribution of methicillin resistant } \\
\text { staphylococcus aureus isolated from different clinical } \\
\text { specimen }(n=713) \text {. } \\
\text { Chi-square }=78.2 \\
\text { Probability }=0.000 \text { (statistically significant difference) }\end{array}$} \\
\hline
\end{tabular}

\begin{tabular}{|l|c|c|}
\hline \multirow{2}{*}{ Technique } & \multicolumn{2}{c|}{ Mec A Gene Positive } \\
\hline Latex Agglutination & No. & \%age \\
\hline PCR & 87 & 94.50 \\
\hline Table-III. Frequency of mecA gene positivity by latex \\
agglutination technique and PCR technique among \\
MRSA isolates (n=92).
\end{tabular}

Table-IV shows the comparison of latex agglutination technique with $\mathrm{PCR}$ technique for detection of mecA gene in MRSA isolates. When compared with PCR (gold standard), latex agglutination showed $100 \%$ sensitivity, and the specificity was $50 \%$. The positive predictive value of the test was $94.25 \%$ and the negative predictive value was $100 \%$. The overall diagnostic accuracy of latex agglutination test was $94.57 \%$. 


\begin{tabular}{|c|c|c|c|c|}
\hline & & \multicolumn{2}{|c|}{ PCR } & \multirow{2}{*}{ Tota } \\
\hline & & Positive & Negative & \\
\hline \multirow{2}{*}{$\begin{array}{l}\text { Latex } \\
\text { Agglutination }\end{array}$} & Positive & 82 & 5 & 87 \\
\hline & Negative & 0 & 5 & 5 \\
\hline \multicolumn{2}{|c|}{ Total } & 82 & 10 & 92 \\
\hline \multicolumn{5}{|c|}{$\begin{array}{c}\text { Table-IV. Comparison of Latex Agglutination } \\
\text { technique with PCR technique for detection of mecA } \\
\text { gene in MRSA isolates }(n=92) \text {. }\end{array}$} \\
\hline
\end{tabular}

\begin{tabular}{|c|c|c|}
\hline Statistics: & \multicolumn{2}{|c|}{$\begin{array}{c}\text { Confidence } \\
\text { Interval (95\% } \\
\text { Cl) }\end{array}$} \\
\hline & Value (\%) & $\begin{array}{c}100.00 \%- \\
100.00 \%\end{array}$ \\
\hline & 100.00 & $\begin{array}{c}39.78 \%- \\
60.22 \%\end{array}$ \\
\hline Specificity & 50.00 & $\begin{array}{c}89.49 \%- \\
99.01 \%\end{array}$ \\
\hline Positive predictive value & 94.25 & $100.00 \%-$ \\
\hline Negative predictive value & 100.00 & $100.00 \%$ \\
\hline Diagnostic Accuracy & 94.57 & $89.94 \%-$ \\
$99.2 \%$
\end{tabular}

\section{DISCUSSION}

MRSA is probably the most disputing bacterial pathogen that presently distresses patients both in community and hospital settings. Globally, vivid rise in MRSA burden has proposed a serious difficulty in selection of antibiotics used for the treatment of infections caused by this super bug. In coming days, we will be in danger of untreatable infections because of resistance to available antibiotics along with continuous decline in the development of anti-bacterial to an unacceptable level globally. The new antibiotics are required to fight with the emerging threat of infections caused by resistant strains. Deliberate and coordinated action is needed to ensure constant availability of effective antibiotics..$^{21,22}$

Here comes the importance of swift and precise detection of methicillin resistance in Staphylococcus aureus (MRSA) in clinical microbiology laboratories not only for opting the appropriate antibiotic therapy for the individual patient but also to avoid treatment failure as well as to control the endemicity of MRSA. ${ }^{23}$
Phenotypically, a wide-range of techniques have been established for detection of methicillin resistance in Staphylococcus aureus that may vary in sensitivity and specificity. Additionally, these methods may not certify proper and timely treatment of all the patients suffering from MRSA infections. Detection of the mecA gene by PCR is the "gold standard", but it's availability and affordability is not ascertained in routine laboratories. ${ }^{24}$ Latex agglutination test for identification of mecA gene product i.e., PBP2a is rapid, sensitive and precise technique for the routine practice in facility constrained laboratories. ${ }^{19}$

In our study we evaluated the diagnostic capacity of latex agglutination method in detecting methicillin resistance in Staphylococcus aureus. Sensitivity, specificity, negative positive predictive values and diagnostic accuracy of this phenotypic method were estimated. Comparison was done against the PCR assay as a gold standard.

Distribution of methicillin resistant Staphylococcus aureus isolates among different clinical specimens is shown in Table-II. Similar studies have been conducted locally as well as abroad. Many researchers have reported higher frequency of MRSA isolated from pus and wound swabs. ${ }^{25,26}$ Maximum number of MRSA $(57.69 \%)$ isolated from endotracheal secretions and CV catheters documented by Mir et al., (2017) from Lahore. These findings are in contrast with our study. ${ }^{27}$

Frequency of mecA gene as detected by latex agglutination technique and PCR technique among MRSA isolates $(n=92)$ is shown in Table-III. According to this table, among total 92 MRSA isolates 87 were mecA gene positive by latex agglutination (94.50\%) while on PCR 82 were detected positive for mecA gene (89.10\%). However, statistically the difference was non-significant $(p>0.05)$. So, among total 92 cefoxitin resistant MRSA isolates, 10 (10.86\%) mecA negative isolates were falsely identified as resistant. These 10 false positive results could probably be liable to the existence of alternate resistance mechanisms i.e., MODSA are the moderately resistant Staphylococcus aureus 
isolates with alterations in the existing PBPs and / or BORSA are the penicillinase hyper-producer strains referred to as borderline oxacillin resistant Staphylococcus aureus.

Table-IV of our study demonstrates the comparison of latex agglutination technique with PCR for detection of mecA gene in MRSA isolates $(n=92)$. The sensitivity, specificity, positive predictive value, negative predictive value and diagnostic accuracy of latex agglutination and PCR are shown below Table-IV. According to our study sensitivity is $100 \%$ and specificity is $50 \%$, PPV is $94.25 \%$ and NPV is $100 \%$. The overall diagnostic accuracy of the tests is $94.57 \%$. Many researchers have reported $100 \%$ sensitivity in accordance to our study.

Similar study by Palavecino, (2014) have reported $100 \%$ sensitivity of latex agglutination test for detection of PBP2a in Staphylococcus aureus. These findings are in comparison with our study. ${ }^{28}$

The findings of Hassoun et al., (2017), have revealed $97 \%$ sensitivity and $100 \%$ specificity of latex agglutination test for correctly identifying MRSA from MSSA. The specificity reported in our study is $50 \%$ which incriminates selectively taking MRSA strains for the study, as well as the very small number of mecA gene negative isolates. ${ }^{6}$

Study carried out by Panda et al., (2016) and Anand et al., (2009), have shown 100\% sensitivity of phenotypic methods when evaluated by genotypic methods for detection of mecA gene in MRSA. Findings of these researchers are in accordance with our study. ${ }^{29,30}$

In the present study, we found that out of 92 cefoxitin resistant MRSA strains, 82 stains were mecA gene positive on PCR and 10 strains were mecA negative. Similar study carried out by Demir et al., (2016) and Jindamwar et al., (2016) have shown $93 \%$ and $90 \%$ MRSA isolates to be mecA gene positive by PCR technique..$^{31,32}$

Evaluation study by Kali et al., (2014) has documented that among 102 cefoxitin resistant
MRSA isolates, only $92(90.1 \%)$ isolates were positive for the mecA gene by PCR. ${ }^{33}$

Other studies have shown even higher mecA negative isolates. ${ }^{30}$ It has been shown in various studies that MRSA with a novel Mec A homologue called as mecC have been recorded in different parts of the world. These isolates are resistant to cefoxitin but show negative results for mecA on PCR. ${ }^{34}$

\section{CONCLUSION}

Effectual scrutiny of the pathogen is required to deal with its emerging public health threat worldwide. The development of diagnostic technologies will have fundamental position in providing faster results [often referred to as 'fast clinical microbiology' (FCM)] to support antimicrobial stewardship programs (ASPs). For the early and precise identification of MRSA, Cefoxitin disc diffusion method must be used with another reliable method preferably latex agglutination test in routine clinical microbiology laboratories with resource limited settings as an alternative to PCR. This will help us to enhance and facilitate the detection of methicillin resistance in Staphylococcus aureus and finally aid for its control of spread.

\section{ACKNOWLEGMENT}

I confer my gratitude to my supervisors for their guidance and whole hearted support, throughout the project.

Copyright $(10$ Oct, 2019.

\section{REFERENCES}

1. McGuinness WA, Malachowa N, DeLeo FR. Focus: Infectious diseases: Vancomycin resistance in Staphylococcus aureus. The Yale journal of biology and medicine. 2017 Jun; 90(2):269.

2. Nisbet M. The superbug crisis: False beliefs about antibiotics are a global threat. Skeptical Inquirer. 2016 Feb 18. CDC, 2017.

3. World Bank. 2016. Drug-Resistant infections: A threat to our economic future (Discussion Draft). Washington, DC: World Bank. Available online at http:// pubdocs.worldbank.org/en/527731474225046104/ AMR-Discussion-Draft-Sept18updated.pdf. 
4. World Health Organization (WHO). 2016. Antimicrobial resistance: Fact sheet no. 194. Genebra: WHO. Retrieved June 20, 2012, from http://www.who.int/ mediacentre/factsheets/fs194/en/

5. Hassoun A, Linden PK, Friedman B. Incidence, prevalence, and management of MRSA bacteremia across patient populations-a review of recent developments in MRSA management and treatment. Critical Care. 2017 Dec; 21(1):211.

6. Gnanamani A, Hariharan P, Paul-Satyaseela M. Staphylococcus aureus: Overview of bacteriology, clinical diseases, epidemiology, antibiotic resistance and therapeutic approach. Frontiers in Staphylococcus aureus. 2017 Mar 8:4-28.

7. Ray MD, Boundy S, Archer GL. Transfer of the methicillin resistance genomic island among staphylococci by conjugation. Molecular microbiology. 2016 May; 100(4):675-85.

8. Singh S, Malhotra R, Grover P, Bansal R, Galhotra S, Kaur $R$, Jindal N. Antimicrobial resistance profile of methicillin-resistant Staphylococcus aureus colonizing the anterior nares of health-care workers and outpatients attending the remotely located tertiary care hospital of North India. Journal of laboratory physicians. 2017 Oct; 9(4):317.

9. Grema HA, Geidam YA, Gadzama GB, Ameh JA, Suleiman A. Methicillin resistant Staphyloccus aureus (MRSA): a review. Adv Anim Vet Sci. 2015; 3(2):79-98.

10. Whittington MD, Curtis DJ, Atherly AJ, Bradley CJ, Lindrooth RC, Campbell JD. Screening test recommendations for methicillin-resistant Staphylococcus aureus surveillance practices: A cost-minimization analysis. American journal of infection control. 2017 Jul 1; 45(7):704-8.

11. Dupieux C, Bouchiat C, Larsen AR, Pichon B, Holmes M, Teale C, Edwards G, Hill R, Decousser JW, TrouilletAssant S, Petersen A. Detection of mecC-positive staphylococcus aureus: What to expect from immunological tests targeting PBP2a?. Journal of clinical microbiology. 2017 Jun 1; 55(6):1961-3.

12. Manjunath, N., Banu, F., Chopra, A., Kumar, P. and Nishana, F., 2017. Management of MRSA patients on the dental chair. Int. J. Res. Med. Sci., 5(8): 3729-3733.

13. Kumurya, A.S., Use of mannitol salt agar (MSA) and cefoxitin as a selective culture medium for growing MRSA Strains. Frontiers in Biomedical Sciences. 2017; 2(1):1-5
14. Liu J, Chen D, Peters BM, Li L, Li B, Xu Z, Shirliff ME. Staphylococcal chromosomal cassettes mec (SCCmec): a mobile genetic element in methicillinresistant Staphylococcus aureus. Microbial pathogenesis. 2016 Dec 1; 101 :56-67.

15. Xu, Z., Miao, J., Lin, C.W. and Li, B., and Lin Li1, 3 (www. avidscience.com) 2017.

16. Cheesbrough M. District laboratory practice in tropical countries. Cambridge university press; 2006.

17. Clinical and Laboratory Standards Institute (CLSI). M100-S26. Performance standards for antimicrobial susceptibility testing: 26th informational supplement. CLSI, Wayne, PA; 2016.

18. Arshad F, Javed I, Mushtaq S. Detection of MecA mediated methicillin resistance in Staphylococcus aureus by cefoxitin disc diffusion method and latex agglutination test. Medicine. 2016; 10:20.

19. Carretto E, Visiello R, Nardini P. Methicillin resistance in staphylococcus aureus. InPet-To-Man Travelling Staphylococci 2018 Jan 1 (pp. 225-235). Academic Press.

20. Patil NR, Ghorpade MV. Comparison of conventional phenotypic methods for detection of methicillin resistant Staphylococcus aureus. Int J Res Dev Pharm Life Sci. 2016; 5:2039-44.

21. Bonate P. Editorial to the themed issue on focus on infectious disease. Journal of Pharmacokinetics and Pharmacodynamics. 2017 Apr 1;44(2):67.

22. Adhikari R, Pant ND, Neupane S, Neupane M, Bhattarai R, Bhatta S, Chaudhary R, Lekhak B. Detection of methicillin resistant Staphylococcus aureus and determination of minimum inhibitory concentration of vancomycin for staphylococcus aureus isolated from pus/wound swab samples of the patients attending a tertiary care Hospital in Kathmandu, Nepal. Canadian Journal of Infectious Diseases and Medical Microbiology. 2017; 2017.

23. Ghanwate N, Thakare P, Bhise PR, Gawande S. Colorimetric method for rapid detection of Oxacillin resistance in Staphylococcus aureus and its comparison with PCR for mec A gene. Scientific reports. 2016 Mar 10;6(1):1-5.

24. Ranjan, K.P., Ranjan, N. and Gandhi, S. Surgical site infections with special reference to methicillin resistant Staphylococcus aureus: Experience from a tertiary care referral hospital in North India. Int. J. Res. Med. Sci. 2017;1(2):108-111. 
25. Rashmi MS, Krishna S, Qayoom S. Prevalence of MRSA among Clinical Isolates of Staphylococcusaureus and its Antibiotic Susceptibility Pattern at a Tertiary Care Hospital. Int JCurrMicrobiol App Sci. 2017;6:7479.

26. Ajmal AN, Mir F, Aslam M, Hafeez R, Attique R. Nosocomial methicillin resistant staphylococcus aureus frequency in a tertiary care hospital, Lahore, Pakistan. Biomedica. 2009 Jul; 25(2):97-100.

27. Palavecino EL. Rapid methods for detection of MRSA in clinical specimens. InMethicillin-resistant Staphylococcus aureus (MRSA) protocols 2014 (pp. 71-83). Humana Press, Totowa, NJ.

28. Panda RK, Mahapatra A, Mallick B, Chayani N. Evaluation of genotypic and phenotypic methods for detection of methicillin resistant Staphylococcus aureus in a tertiary care hospital of Eastern Odisha. Journal of clinical and diagnostic research: JCDR. 2016 Feb; 10(2): DC19.

29. Anand KB, Agrawal P, Kumar S, Kapila K. Comparison of cefoxitin disc diffusion test, oxacillin screen agar, and PCR for mecA gene for detection of MRSA. Indian journal of medical microbiology. 2009 Jan 1; 27(1):27.
30. Demir T, Coplu N, Esen B. Comparative analysis of phenotypic and genotypic detection of methicillin resistance among Staphylococcus aureus. Indian Journal of Pathology and Microbiology. 2016 Jul 1; 59(3):314.

31. Jindamwar P, Roy P, Chaudhary CN, Grover N, Shivraj $P$, Atul K. Novel Reporting of Community Acquired Methicillin Resistant Staphylococcus aureus (CAMRSA) Strain at a Tertiary Care Centre. International Journal of Current Microbiology and Applied Sciences. 2016; 5:555-64.

32. Kali A, Stephen S, Umadevi S. Laboratory evaluation of phenotypic detection methods of methicillinresistant Staphylococcus aureus. Biomedical journal. 2014 Nov 1; 37(6).

33. Kriegeskorte A, Idelevich EA, Schlattmann A, Layer F, Strommenger B, Denis O, Paterson GK, Holmes MA, Werner G, Becker K. Comparison of different phenotypic approaches to screen and detect mecCharboring methicillin-resistant Staphylococcus aureus. Journal of clinical microbiology. 2018 Jan 1; 56(1): e00826-17.

\begin{tabular}{|c|c|c|c|}
\hline \multicolumn{4}{|c|}{ AUTHORSHIP AND CONTRIBUTION DECLARATION } \\
\hline Sr. \# & Author(s) Full Name & Contribution to the paper & Author(s) Signature \\
\hline 1 & Aneela Khawaja & $\begin{array}{l}\text { Entire research work, Literatue } \\
\text { review, Mathodology, Analysis } \\
\& \text { write up. }\end{array}$ & \\
\hline 2 & Iffat Javed & $\begin{array}{l}\text { Supervision of whole research } \\
\text { project \& help in write up. }\end{array}$ & \\
\hline 3 & Sohaila Mushtaq & Help in write up. & \\
\hline 4 & Saeed Anwar & $\begin{array}{l}\text { Result compilation \& help in } \\
\text { data analysis. }\end{array}$ & \\
\hline 5 & Faiqa Arshad & Proof reading. & \\
\hline 6 & Naseer Ahmad Raja & Proof reading. & \\
\hline
\end{tabular}

